\title{
Increasing fish diversity of Chicago's waterways
}

\author{
Austin Happel ${ }^{*}$ (1) \\ Daniel P. Haerther Center for Conservation and Research. John G. Shedd Aquarium, Chicago, IL, USA
}

\begin{abstract}
Received: 12 August 2021 / Accepted: 23 December 2021
Abstract - Descriptions of shifts in biodiversity across time are desired for urban freshwater systems to better study ecosystem change and causal mechanisms. I document changes in fish diversity within the Chicago Area Waterways across 35 years using a battery of diversity metrics calculated on both abundance and biomass data. Has diversity of Chicago's waterways changed over 35 years and if so, do different diversity metrics exhibit different trends or breakpoints in trends? Diversity of the fish assemblage increased across the three decades of study. Breakpoint analysis suggested that trends across the timeseries were nonlinear. Changes in dominant species influenced behavior of less traditional metrics, whereas Margalef's Richness, Shannon-Weiner, and Gini-Simpson appeared more robust. Increases in richness and taxonomic diversity combined with decreases in species dominance suggest an ecosystem of increasing quality. The fish community of the Chicago Area Waterway System is more diverse both in abundance as well as biomass (i.e., energy flows) in the late 2010's than it was in the late 1980's. Although external factors related to wastewater treatment increased water quality and likely led to these assemblage-level changes breakpoint analysis did not allow verification of causal mechanisms.
\end{abstract}

Keywords: Abundance-biomass curves / fish diversity / timeseries / urbanization / urban ecosystem / working waterways

\section{Introduction}

There is a growing need to understand patterns in species diversity of urban ecosystems if we are to better predict and manage future responses as global human populations continue to increase and urbanize (Richardson and Whittaker, 2010). Changes to species assemblage structures, induced through compounding natural and human pressures, can lead to ecosystems locked in undesirable ecological states (Folke et al., 2004; Scheffer and Carpenter, 2003). Of particular interest are freshwater systems in urban landscapes, which represent some of the world's most altered and damaged environments while simultaneously being among the most vulnerable systems to future changes in climate and anthropogenic pressures (Booth et al., 2016; Capon et al., 2013; Everard and Moggridge, 2012; Vörösmarty et al., 2010; Walsh et al., 2005). Freshwater fauna across the globe have been shown to exhibit greater declines in biodiversity than terrestrial ecosystems, largely due to human utilizations and alterations of freshwater resources (Albert et al., 2020). Monitoring trends, shifts, and stability of freshwater fish assemblages is a useful preliminary step in interpreting effects of exogenous changes (i.e., policy or land-use changes) on

\footnotetext{
*Corresponding author: ahappel@sheddaquarium.org
}

aquatic ecosystems (Dodds et al., 2012; Magurran et al., 2010; Roberts et al., 2020).

Community and assemblage-level responses to humaninduced events and practices have been described to be resistant (i.e., no change) or to vary from linear changes to sudden, sharp, threshold-induced restructurings (Bestelmeyer et al., 2011; Connell and Sousa, 1983; deYoung et al., 2008; Gordon et al., 2008; Holling, 1973). For example, Bouska et al. (2020) identified sets of desired vs. undesired steadystate regimes with feedback mechanisms resisting change from the undesired regime in the Upper Mississippi River Basin. Capon et al. (2015) found little evidence for sharp transitions between steady-state regimes in freshwater systems outside of shallow temperate lakes shifting between macrophyte and phytoplankton dominant states. Instead, monotonic trajectories, like the gradual increase in fish species richness noted in the Illinois River after enacting the Clean Water Act (Gibson-Reinemer et al., 2017), seem more common in freshwater systems (Capon et al., 2015). A potential reason might be that responses of riverine fish assemblages to management actions are on the order of decades (DeBoer et al., 2019), rather sudden, sharp, threshold-induced restructurings. As such, long-term monitoring of species assemblages is necessary to be able to capture and interpret cumulative responses to management (Dodds et al., 2012). 
While continuous gradual shifts may be assessed with regressions, the complex behavior (i.e., changes in regimes or trajectories) of communities over time may not be captured. Regime shift analysis typically focuses on shifts in means, and thus from one steady-state regime to another in a relatively short timescale (deYoung et al., 2008; Rodionov, 2004). For example, changes in mean principle component scores was used to identify regime shifts two years after Dreissenid mussel colonization in Lake Ontario (Nicholls et al., 2011). Changes in means however does not capture time periods of active transition nor trend reversals. For example, Znachor et al. (2018) illustrate a variety of community responses (i.e., linear, piecewise, and regime shifts) within a suite of environmental variables from a freshwater reservoir timeseries. Piecewise regression or breakpoint analysis may better capture both steady-state periods as well as periods of transition (Zeileis et al., 2003, 2010). Identification of periods of transition vs. periods classified as regimes, can aide in identifying drivers of changes as well as management actions to avoid undesirable regimes.

The Chicago Area Waterway System (CAWS) is composed of over 76 miles of dredged, reconfigured, or rerouted waterways, tied to the waste- and storm-water systems of the surrounding city of Chicago (Greenberg, 2004; Hill, 2019; LimnoTech, 2010; Solzman, 2006). Since enactment of the Clean Water Act, the Metropolitan Water Reclamation District of Greater Chicago (MWRD) has made several improvements to the waste- and storm-water systems integrated with the CAWS, towards waterways that are fishable and swimmable, a stipulation of the Clean Water Act (Karr and Dudley, 1981). Using log-linear models, Happel and Gallagher (2021) illustrated that since 1985 abundances of many fish species have increased throughout the CAWS. Whether or not breakpoints or piecemeal trends in diversity metrics exist in the system remains of interest, especially if breakpoints in trends correspond temporally to known changes to waste- and storm-water management.

As biodiversity has multiple meanings and is difficult to capture through any single number (Gallardo et al., 2011; Lyashevska and Farnsworth, 2012), I use a battery of diversity metrics to describe trends of a fish assemblage in an urban waterway that has been monitored over three and half decades. Of interest was whether the fish assemblage exhibited increasing diversity and identifying if trends across time exhibited breakpoints. Identifying historic patterns in biodiversity is an important first step in a larger goal of linking policy-level changes, management activities, environmental variables, and species responses together.

\section{Methods}

\subsection{Study system}

As described by Happel and Gallagher (2021):

The CAWS consists of two rivers (Chicago River and Calumet River) whose flows have been reversed, connected by two man-made canals (Chicago Sanitary and Ship Canal and the Cal-Sag Channel), which all eventually flow south to the Illinois River. An additional constructed canal, the North Shore Channel, supplies water, via discretionary flow, from Lake Michigan aiding the flow of water through the channel through the northern Chicago communities towards downtown (Illinois Coastal Management Program, 2011). Other inlets from Lake Michigan are located on the Chicago River (Chicago River Control Works) and the Calumet River (T.J. O'Brien Lock and Dam) help to maintain adequate flows and water levels in the CAWS. The CAWS includes outflows from four wastewater treatment plants (Terrence J. O'Brien, Stickney, Lemont, and Calumet), one of them the world's largest (MWRD, 2019), as well as a combined sewer overflow system which releases untreated wastewater into the surface waterways when the tunnel and reservoir sewer system is overwhelmed by heavy rainstorms. The system is generally described as slow flowing, non-wadable, lotic waters with vertical steel walls or near vertical banks, soft fine sediment, and little submerged habitat (LimnoTech, 2010). A more comprehensive description of the study system and its history are summarized well by (Hill, 2019) and (Olson and Morton, 2017).

As part of the Tunnel and Reservoir Plan (known as: TARP), sections of a deep tunnel sewage storage system have periodically become operational since 1985, reducing the amount of untreated waste- and storm- water released into the CAWS (Fig. S1.1 in Appendix S1). In the mid-1990s, five Side-stream Elevated Pool Aeration (SEPA) stations were put in operation(Butts et al., 1999), to increase dissolved oxygen in addition to two already in operation since $\sim 1980$ (Melching, 2018). In the mid 2010's two reservoirs came online to increase waste- and storm-water storage capacity of the system, avoiding further release of untreated water into the CAWS. Improved denitrification, chlorine-disinfection, U.V. sterilization, and phosphorus recovery capacities have been implemented at water reclamation plants in the late 2010's. Each of these management actions has improved water quality of the CAWS system (Pluth et al., 2021).

To assess the efficacy of such improvements on aquatic life, MWRD has monitored fish populations annually throughout the CAWS using electrofishing methods since the 1970's. An expanded sampling program began in 1985, and since then nine sampling locations have been monitored on an annual basis (except 2008, 2014, and 2015) representing six distinct waterway sections (Fig. 1). Only three of the six waterways were sampled in 1997, 1998, 2000 with different waterways sampled each of those years (Tab. S1.1 in Appendix S1). In 2013 only the Chicago Sanitary and Ship Canal and the Lockport Lock and Dam locations were sampled and in 1999 only the North Shore Channel was sampled. Beginning in 2001, alternating current electrofishing was used whereas direct current electrofishing was used 1985-2000; a methodological change which is known to affect what fish are captured (McClelland et al., 2013). A breakpoint was predicted to occur between 2000 and 2001 due to this sampling methodology change.

\subsection{Data}

Data collection and selection is described within (Happel and Gallagher, 2021). Briefly, data consists of 483 samples from nine locations most consistently sampled in July, August, and September over 35 years. A sampling event consisted of separately sampling each side of a 400-m section of river with an electroshocking boat, identifying and measuring (length and mass) all fish possible. Effort was 


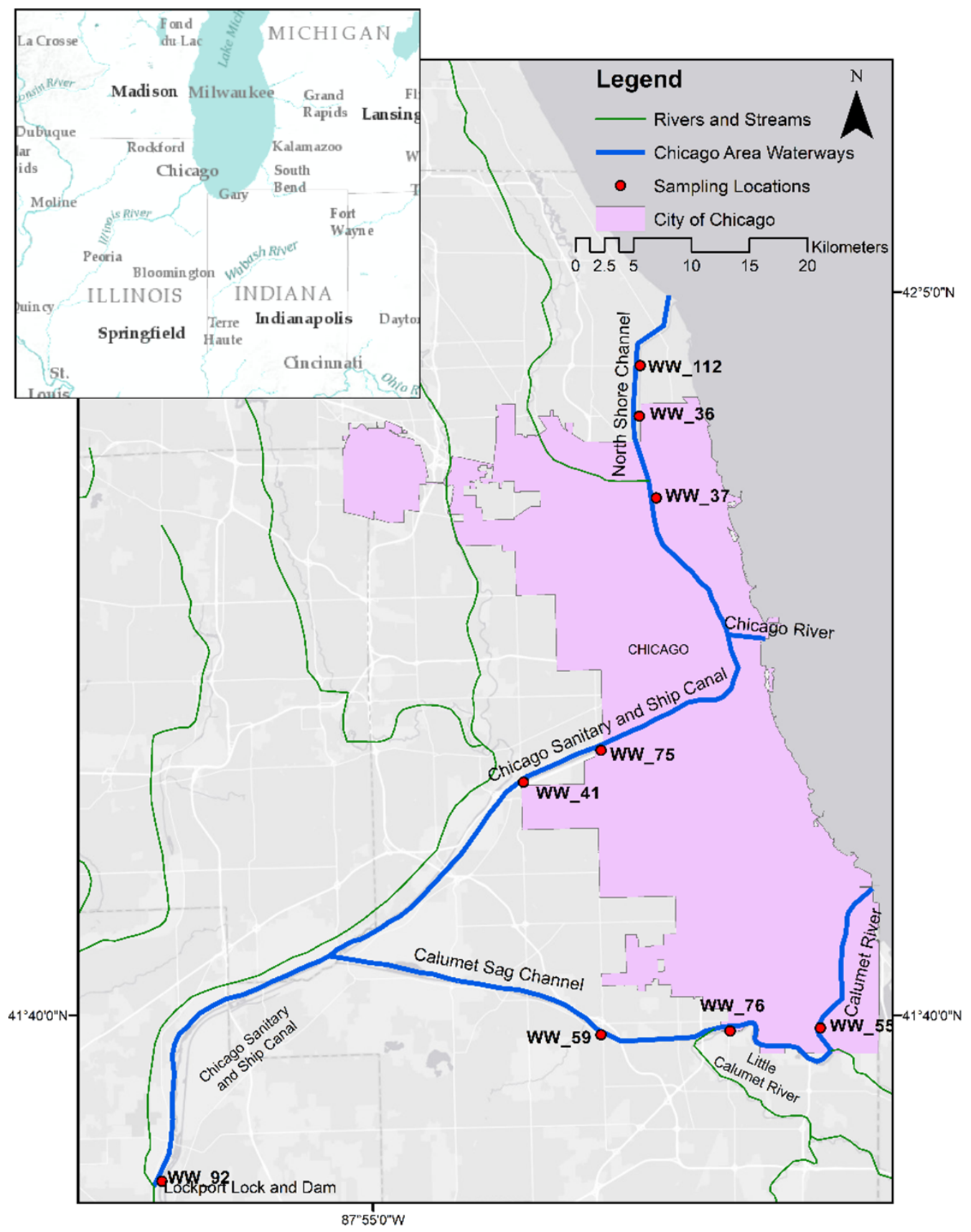

Fig. 1. A map of the locations from which fish were sampled from a 400-ft section of the river, often on both the left and right sides of the mainchannel (two samples per site). Included is an inset denoting major rivers, cities, and states around Chicago. Locations in close proximity were lumped into a waterway grouping (i.e., WW_112, WW_36, and WW_37 for NorthShore Channel; WW_76 and WW_41 for Chicago Sanitary and Ship Canal) for analysis.

recorded in seconds and used to standardize samples to units of 30-min of effort. Data represents catch and mass per unit effort (CPUE and MPUE respectively) for 62 species of fish (Tab. S2.1 in Appendix S2).

Unrecorded masses were imputed using the remaining data to construct length-weight regressions for each species and used to estimate 41 masses out of a total of 58,628 $(0.07 \%)$. Further, I assumed all lengths were recorded correctly and any masses with residuals $>|0.25|$ were errors and thus were subsequently corrected using the length-weight regressions. This corrected 505 masses out of a total of 58,628 $(0.86 \%)$ and maintained an r-squared value of 0.999 between uncorrected and corrected values. Due to the low percentage of total changes $(546 / 58,628=0.93 \%)$, this was considered to provide a complete biomass dataset without overly introducing bias. 


\subsection{Analysis}

A series of alpha-diversity indices were calculated as described in Table 1. Margalef's Richness, Shannon-Wiener H Index, Gini-Simpson Index, Pielou's evenness and Berger-Parker Index together describe diversity on a spectrum of focus from richness to evenness or dominance, and thus differing descriptions of the assemblage. For example, the Shannon-Wiener index is more sensitive to rare species whereas the Gini-Simpson and Berger-Parker indices are more sensitive to numerically dominant species.

Incorporating taxonomy into diversity indices may provide a differing view of how diversity of a system changes over time as related species often have related responses to stressors (Clarke and Warwick, 1999, 2001a). The length across a Linnaean taxonomic tree was calculated for each species in a sample and averaged, yielding average taxonomic diversity $\left(\Delta^{+}\right)$for each sample. Variation in taxonomic distinctness $\left(\Lambda^{+}\right)$ is calculated as the variance in the lengths between all pairs of species within a sample, importantly it is not variation in $\Delta^{+}$. Both metrics function off a species list (presence/absence data) and thus are effort indifferent and lose abundance-related information. I used a taxonomic list including species, genus, family, order, and class for each species with each branch length unweighted and each step between levels considered equal. A species list with species present rather evenly across multiple orders would have increased taxonomic diversity $\left(\Delta^{+}\right)$and decreased variation in taxonomic distinctness $\left(\Lambda^{+}\right)$ compared to a similar list but includes a very specious genus (Clarke and Warwick, 2001a). Increases in taxonomic diversity $\left(\Delta^{+}\right)$and decreases in variation in taxonomic distinctness $\left(\Lambda^{+}\right)$ would be expected as ecosystems recover from disturbed states and species list become more even across higher level classifications.

Warwick's W statistic compares $k$-dominance curves of abundance to biomass of species, the difference of which is summed and scaled to the number of species in the sample allowing comparisons across multiple samples on a scale of disturbed (negative values) to non-disturbed (positive values) (Warwick, 1986). The underlying assumption is that larger heavier individuals in a system indicate less disturbance whereas many individuals of small masses suggest greater perturbations. While the $\mathrm{W}$ statistic was developed with macroinvertebrates (Warwick and Clarke, 1994), it has been shown to indicate environmental impacts on fish assemblages in freshwater systems (Coeck et al., 1993; Penczak and Kruk, 1999; Pinto et al., 2006; Piperac et al., 2015).

Similar to the W Statistic's interpretation, increasing values of mass per fish would indicate a system with lowered mortalities as older fish are generally larger. I analyzed changes in the average mass of individual fish across the timeseries for specific trophic guilds, rather than as a whole. Separation by trophic guilds was done to reduce the influence of Common Carp (Cyprinus carpio) and Goldfish (Carassius auratus), which can attain large sizes even in degraded systems. Fish were classified into trophic guilds based on combining information in published sources (O'Hara et al., 2007; Poff and Allan, 1995). Guilds included Planktivores, Omnivores, General Invertivores, Surface Invertivores, Benthic Invertivores, and Piscivores, although a large majority of species fell under the general Omnivore category. Decreases in mass per individual of Omnivores combined with increases in other guilds is thought to occur with lessening degradation (Fausch et al., 1990).

Finally, an analysis of assemblage-level anomalies was included, as advocated by Nicholls (2011). Prior to calculations, counts and biomasses were transformed by adding 1 and taking the natural logarithm to down weight the importance of highly abundance species. A grand mean community structure was calculated by averaging the transformed biomasses or counts for each species across samples. As some waterways were sampled more frequently in earlier years, data were averaged first to waterway*year combinations, then to year, and finally across years, otherwise earlier assemblages or certain waterways would be overly influential. Each sample was then compared to this grand mean community using the Bray-Curtis similarity index $\left(B C_{i}\right)$. The mean of all samples' Bray-Curtis similarity with the mean community was calculated $(\bar{B} C)$. Anomalies, aka. similarity residuals, were then calculated by subtracting each sample's Bray-Curtis similarity to the average community from the average of all sample's Bray-Curtis similarities (anomaly $_{i}=\overline{B C}-B C_{i}$ ). I analyzed these anomalies directly and, since they essentially represent residuals around a mean, through a cumulative sum (CUSUM) metric, which emphasizes when values change signs or magnitude (Zeileis et al., 2002). The CUSUM metric was calculated, and subsequently analyzed, on the yearly mean anomaly values not the whole dataset.

I calculated all metrics for every sample $(n=483$; except CUSUM $n=32$ ) for both abundance and biomass data, except for the W statistic and mass per individual which used both datasets, and Taxonomic Diversity indices $\left(\Delta^{+}\right.$and $\left.\Lambda^{+}\right)$which used presence/absence data. Thus, I explore trends in yearly mean values of 23 metrics across the 32 years data were collected. Again, as some waterways had more than one sample location or were sampled more in certain years, I averaged data first by each waterway*year pairing and then to each year.

I regressed each metric's annual mean value against year and used residual sum of squares and BIC minimization to assess breakpoints in the regression where groups of samples behaved differently. Differences in behavior identified by breakpoints analysis could be in mean value, in slope and intercept, or a combination of both. The minimum number of observations (i.e., years) per segment was set to 3 to allow for curve fitting. Linear models were used for most metrics, the exceptions being the mass per individuals of trophic guilds which were $\log _{\mathrm{e}}$ transformed prior to curve fitting. I used PRIMER +E software to calculate all indices (Clarke and Gorley, 2015), except that the Bray-Curtis similarities to grand mean assemblage were calculated using the vegan package (Oksanen et al., 2019; R Development Core Team, 2020). Identification of breakpoints, and subsequently $95 \%$ confidence intervals in their estimation, was conducted with the $\mathrm{R}$ package strucchange (Zeileis et al., 2002). Differences in means among segments identified by breakpoints and whether their slopes were significantly different from zero were assessed with the R package emmeans (Lenth et al., 2018). 
Table 1. Summary of the metrics used to assess changes in community composition, where $S=$ the number of species in a sample, $N=$ the number of individuals found in a sample, $n_{i}=$ the number of individuals found of the $i$ th species in a sample, $p_{i}=$ a proportional representation of ith species within a sample (whether abundance [A] or biomass [B]), and $\omega_{i j}=$ the distance between two species $(i$ and $j$ ) on a Linnaean classification tree.

\begin{tabular}{lll}
\hline Metric & Description & Interpretation \\
\hline Margalef's Richness $(d)$ & $\begin{array}{l}\text { Standardizes the number of species found by } \\
\text { sum of the sample. }\end{array}$ & $\begin{array}{l}\text { Higher values represent greater species } \\
\text { richness. }\end{array}$
\end{tabular}

Shannon-Wiener Entropy $(\mathrm{H})$

$$
=-\sum_{i=1}^{S} p_{i} * \ln p_{i}
$$

Pielou's Evenness (J')

$$
=\frac{H}{\log S}
$$

Gini-Simpson Index

$$
=1-\sum_{i=1}^{S} \frac{n_{i} *\left(n_{i}-1\right)}{N *(N-1)}
$$

Berger-Parker Index

$=\max \left(p_{i}\right)$

Average Taxonomic Distinctness (presence/absence data)

$$
\Delta^{+}=\left[\sum \sum_{i<j}\left(\omega_{i j}\right)\right] /[S(S-1) / 2]
$$

Variation in Taxonomic Distinctness (presence/absence data)

$\Lambda^{+}=\left[\sum \sum_{i<j}\left(\omega_{i j}-\Delta^{+}\right)^{2}\right] /[S(S-1) / 2]$

W Statistic

$$
=\frac{\sum_{i=1}^{S} B p_{i}-A p_{i}}{50 *(S-1)}
$$

Mass per Individual

$$
=B_{i} / A_{i}
$$

Assemblage Anomalies

$$
=Y-Y_{i}
$$

Where $Y_{i}=$ Bray-Curtis dissimilarity between sample $i$ and the grand mean of samples
Quantifies the uncertainty in predicting the species identity of an individual (or mass) that is taken at random from the dataset.

Quantifies how equal the community is numerically.

Quantifies probability that two individuals (or masses) drawn at random are from the same species.

The proportional value of the most abundant species.

The average path length $\left(\omega_{\mathrm{ij}}\right)$ traced along Linnaean taxonomic trees between all species pairs in a sample.

The variance of the taxonomic distances (wij) between each pair of species $\mathrm{i}$ and $\mathrm{j}$, about their mean value $\Delta^{+}$.

Quantifies the degree of separation of biomass and abundance $k$-dominance curves.

Total biomass of a sample divided by the number of individuals in the sample.

How similar a sample is to the average of how similar all samples are to the grand mean of the assemblage.
Higher values represent greater species diversity and evenness.

Higher numbers suggest species are present in more equal amounts.

Higher values suggest assemblages are dominated by a few species.

Higher numbers indicate that the most abundant species dominates the assemblage.

Higher values indicate a greater number of species from disparate taxonomic groups.

Increases suggests greater diversity of closely related species, thus decreases suggest higher environmental quality.

Positive values represent non-disturbed states; Negative values represent disturbed states.

Increasing mass per individual would suggest larger, older individuals are more common.

Assemblages vastly different from the mean assemblage structure will have larger (positive or negative) valu`es. 

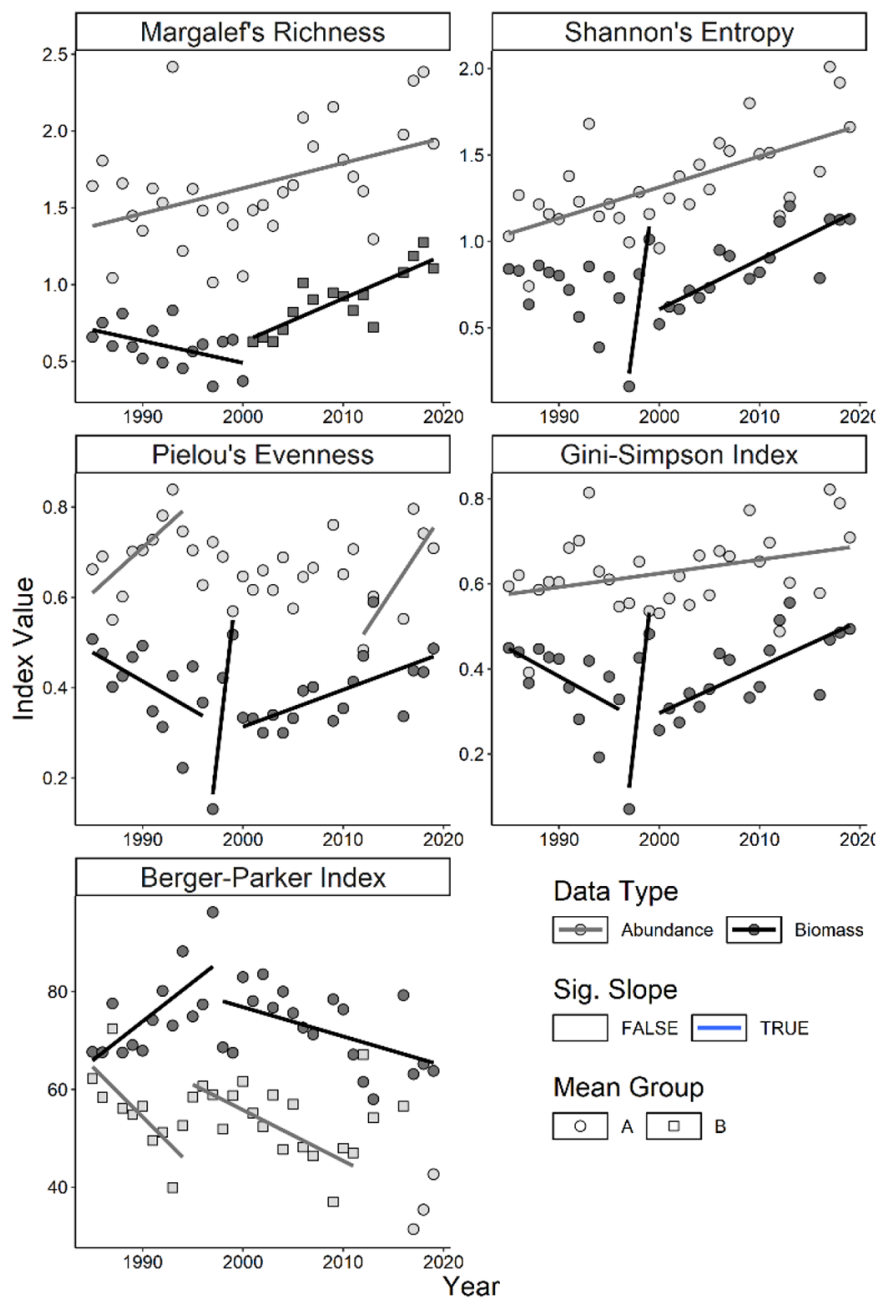

Data Type

$\multimap$ Abundance $\rightarrow$ Biomass

Sig. Slope

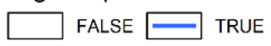

Mean Group

0 A $\square$ B

Fig. 2. Diversity metrics calculated on abundance (CPUEs; grey) and biomass (masses, black) suggest the fish community of the Chicago Area Waterway System is more diverse in 2019 than in 1985, although regressions were not linear. Lines represent significant piecewise regressions (minimum of 3-yr spans; $\alpha=0.05$ ). Different shapes represent groups with significantly different means $(\alpha=0.05)$ within each index.

\section{Results}

Trends for all but five metrics exhibited breakpoints throughout the timeseries. The five metrics which did not exhibit breakpoints: Richness, Shannon-Wiener's H, and the Gini-Simpson index all calculated on abundance data (Fig. 2), as well as average taxonomic distinctness $\left(\Delta^{+}\right.$; Fig. 3$)$, and mass per individual of surface invertivores (Fig. 4). However, each of these five metrics exhibited significant increases over the 35 years $(p s<0.05)$. Of the other metrics, all had significant breakpoints indicating different means, slopes and intercepts, or combinations of both between groups of years $(p s<0.05)$.

Breakpoints were common in 1997 through 1999. Shannon's Entropy, Pielou's Evenness, and Gini-Simpson Index calculated with biomass data (Fig. 2), mass per individual invertivore (Fig. 4), and the W statistic (Fig. 5)

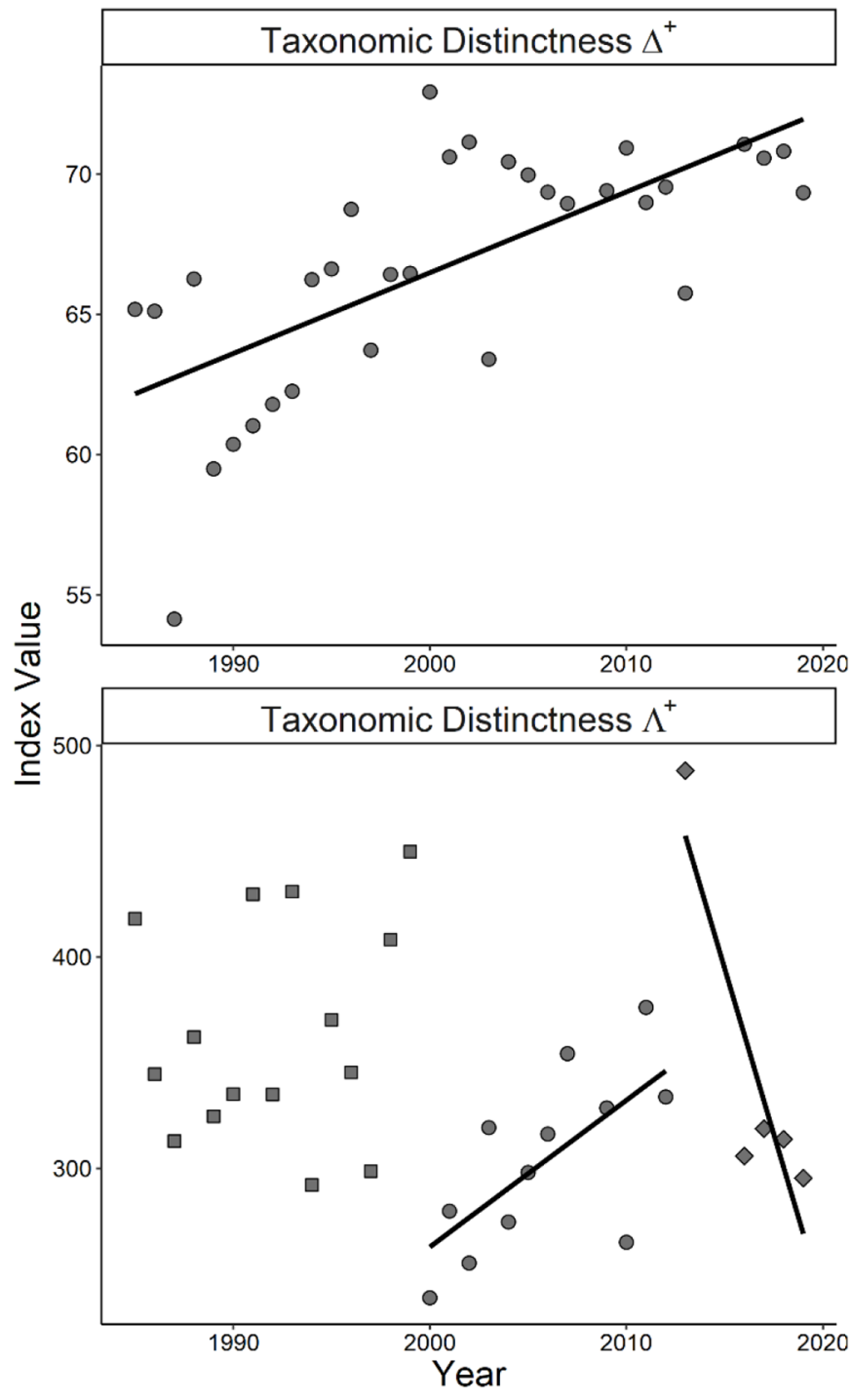

Fig. 3. Changes in yearly mean average taxonomic distinctness $\left(\Delta^{+}\right)$ and taxonomic variability $\left(\Lambda^{+}\right)$over 35 years in the Chicago Area Waterway System indicate a more taxonomically diverse ecosystem in 2019 than 1985. Lines represent significant piecewise regressions (minimum of 3-yr spans; $\alpha=0.05$ ). Different shapes represent groups with significantly different $(\mathrm{A}=$ circles $v s . \mathrm{B}=$ squares $)$ or shared $(\mathrm{AB}=$ diamonds $)$ means $(\alpha=0.05)$ within each index.

all indicated breakpoints from 1996 to 1999. Mass per individual benthic invertivore also had a breakpoint at 1996 but the second one was 2000 (Fig. 4). Berger-Parker Index and Margalef's Richness calculated with biomass indicated a single breakpoint at 1997 and 2000, respectively. A single breakpoint also occurred in the abundance anomalies (1998; Fig. 6) series. Variation in Taxonomic Distinctness had a breakpoint at 1999 but the second breakpoint was in 2012 (Fig. 3). Consensus of the final years of a segment in the breakpoint analysis of yearly trends suggests that assemblagelevel shifts occurred within the late 1990's (Fig. 7).

Yearly mean abundance and biomass (effort standardized, and $\log _{\mathrm{e}}$ transformed) for each species were investigated using heat-map style plots to help infer species responsible for 


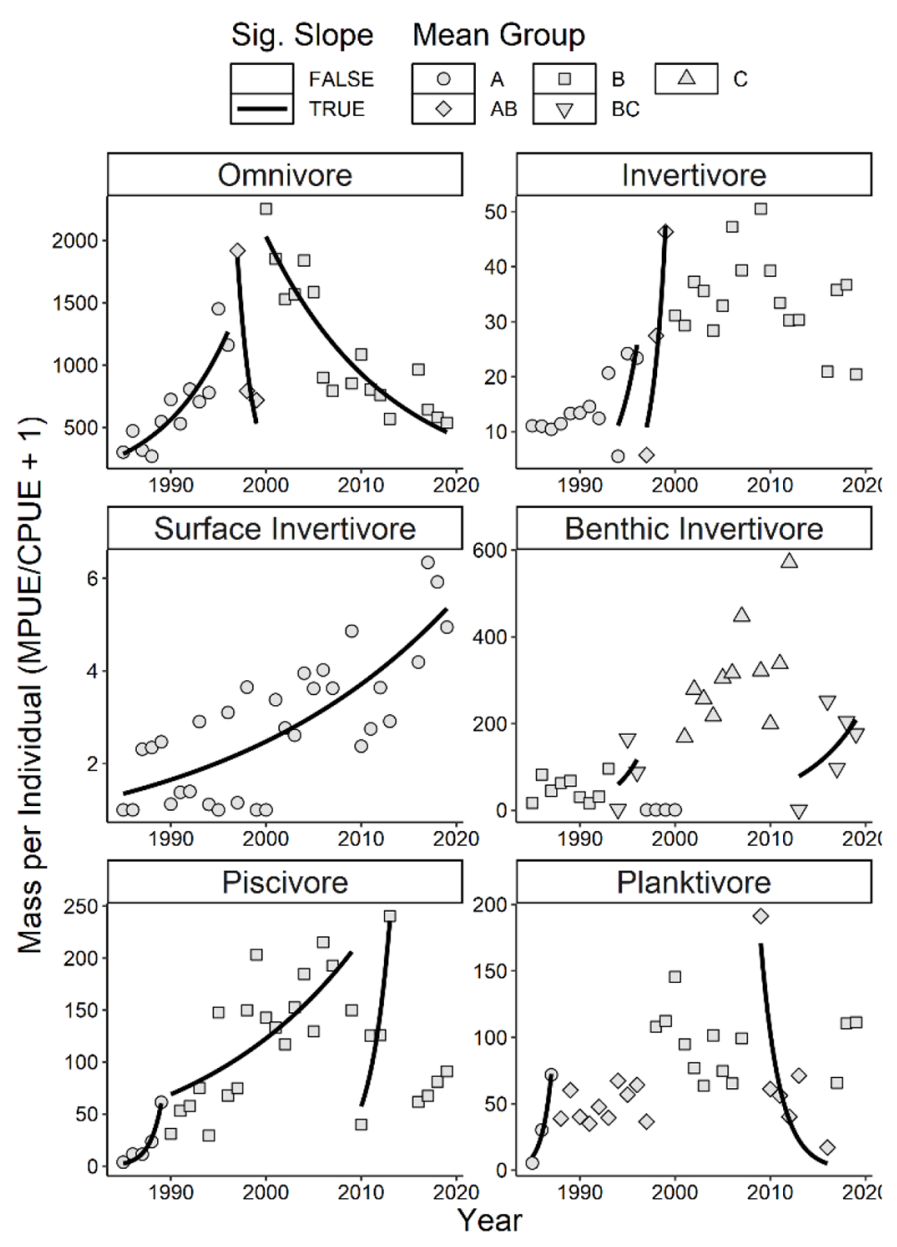

Fig. 4. Mean mass per individual fish for different trophic guilds generally increased over 35 years in the Chicago Area Waterway System, except for omnivorous species which is generally thought of as a sign of increases ecosystem quality. Lines represent significant piecewise regressions (minimum of 3-yr spans; $\alpha=0.05$ ). Different shapes represent groups with significantly different means $(\alpha=0.05)$ within each index.

assemblage-level changes (Figs. 8 and 9). Gizzard Shad (Dorosoma cepedianum) were the most abundant species ( $28.8 \%$ of total count) and thus the Berger-Parker index on abundance closely follows changes in Gizzard Shad populations. Gizzard Shad were also the second greatest contributor to biomass ( $7.4 \%$ of total biomass). The highest abundances of Gizzard Shad occurred in 2012 (mean $C P U E=296$ ) and 2016 (mean $C P U E=227$ ). Common Carp were the most dominant by biomass throughout the timeseries (77.9\% of total) but comprised only $8.0 \%$ of the total count. The Berger-Parker index on biomass closely follows changes in Common Carp populations. Common Carp biomass increased by a factor of 8 between 1999 (mean MPUE $=3345$ g) and 2000 (mean MPUE $=27,707 \mathrm{~g}$ ) and peaked in 2016 (mean MPUE $=62,110 \mathrm{~g}$ ). Bluegill (Lepomis macrochirus), Common Carp, Green Sunfish (Lepomis cyanellus), and Largemouth Bass (Micropterus salmoides) were the only species to be found every year of survey.

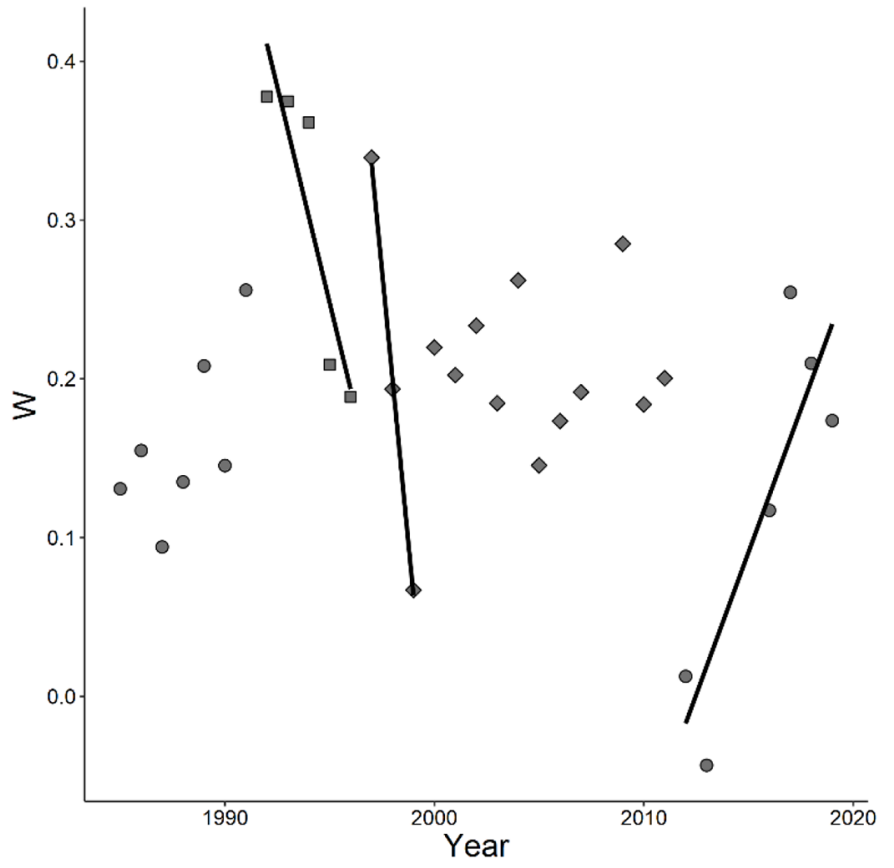

Fig. 5. Changes in yearly means of Warwick's W statistic (ABC curves) over 35 years in the Chicago Area Waterway System. Positive values are considered indicative of un-disturbed environments (i.e., fewer larger individuals) whereas negative values indicate more disturbance (i.e., highly abundant small individuals), values near zero are non-conclusive. Lines represent significant piecewise regressions (minimum of 3-yr spans; $\alpha=0.05$ ). Different shapes represent groups with significantly different $(\mathrm{A}=$ circles $v s . \mathrm{B}=$ squares $)$ or shared $(\mathrm{AB}=$ diamonds $)$ means $(\alpha=0.05)$.

\section{Discussion}

Biodiversity of the fish assemblage in the CAWS generally increased across the 1985-2019 timeseries. Abundance, biomass, and even presence-absence data indicated that diversity is higher in 2019 than in 1985 (Figs. 2 and 3). Traditional theory suggests greater numbers and diversity of species, combined with lower dominance by any one species, equates to an environment meeting varied needs, including reduced stressor frequency and intensity, and thus higher quality (Barbour, 1999; Fausch et al., 1990; Karr and Dudley, 1981; Washington, 1984). Analyses presented here suggest that diversity of the CAWS fish assemblage has increased regardless of whether it was calculated on presence/absence, abundance, or biomass metrics. As such, the fish assemblage of the CAWS indicates a system of increasing health or biotic integrity realized through increased fish diversity in 2019 compared to 1985 .

Known changes in landscape level waste- and storm-water management may offer preliminary explanations to why breakpoints in assemblage structures were evident. For example, changes in discharge patterns elicited shifts in submerged vegetation as well as a coinciding shift in fish assemblages in the Upper Mississippi River (Burdis et al., 2020; Giblin, 2017). For the CAWS, five side-stream elevated 


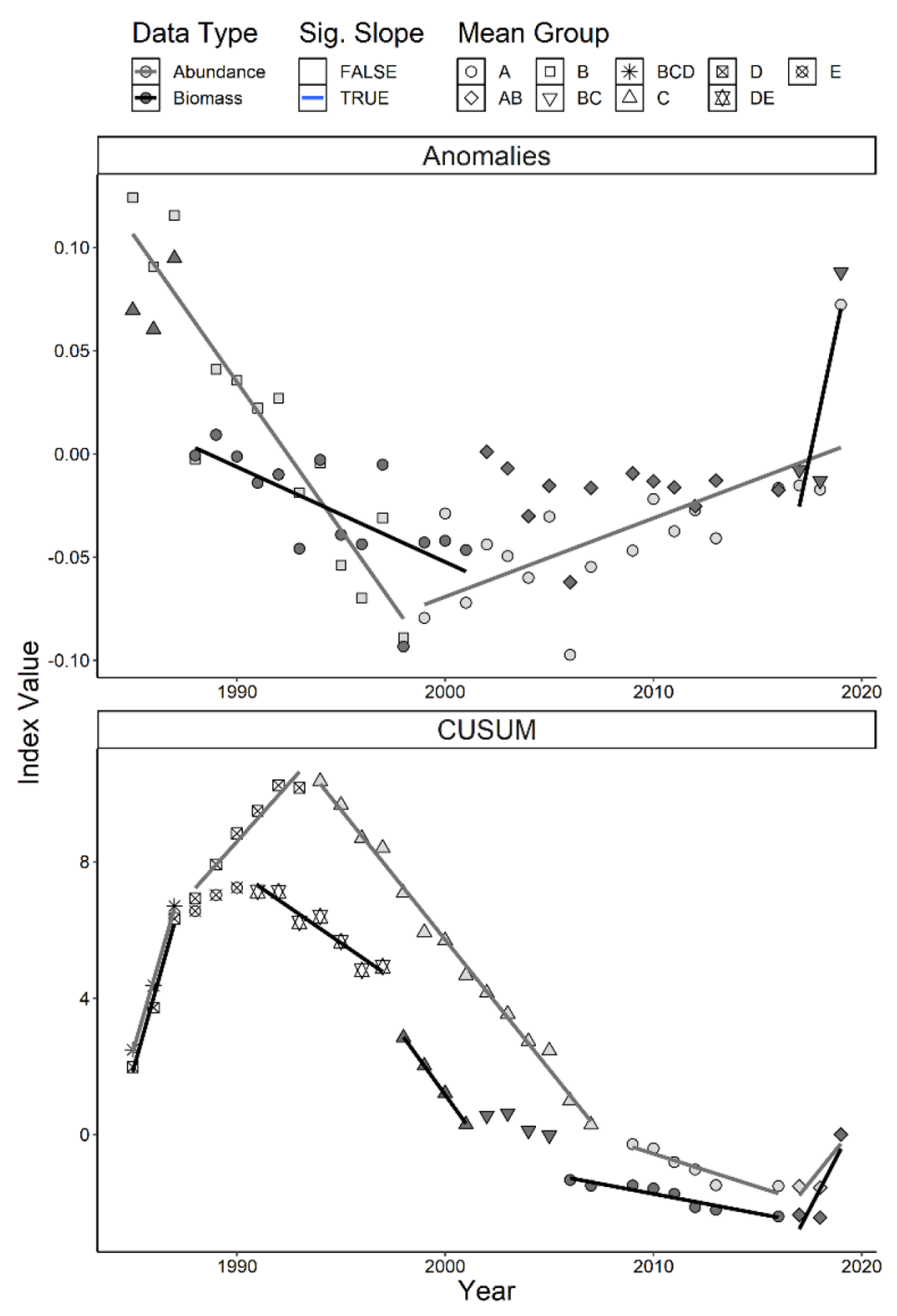

Fig. 6. Yearly mean fish assemblage anomalies (similarity to the grand mean assemblage) and their cumulative sum (CUSUM) over 35 years in the Chicago Area Waterway System, calculated using abundance (grey) and biomass (black) data identify the late 1980s and late 1990's as periods of rapid change. Lines represent significant piecewise regressions (minimum of 3-yr spans; $\alpha=0.05$ ). Different shapes represent groups with significantly different means $(\alpha=0.05)$ within each index.

aeration stations became operational in 1994, a targeted measure to decrease anoxic events (Butts et al., 1999). It is possible that increased aeration of the CAWS contributes to the assemblage-level changes noted in late 1990's. Greater disinfection practices of wastewater effluent starting in 2015 and 2016 for two of the three large treatment plants in the area (Fore, 2015b, 2015a), the Thornton Composite Reservoir becoming operational holding 7.9 billion gallons of untreated wastewater during storm events (Sheet, n.d.) in 2015, and the addition of a phosphorus recovery system in 2016, also likely contribute to the breakpoints noted in the late 2010's (Fig. S1.1 in Appendix S1). Together such policy and management changes likely have incrementally increased water quality of the CAWS, their intended goal (Fore, 2015a), and subsequently altered fish diversity, however specific statistical linkages have not been established.
As different indices highlight different aspects of a species assemblage, using any one in isolation may miss important changes in the system. This seems particularly true when using abundance data without considering biomass changes (Connolly et al., 2005; Henderson and Magurran, 2010; Morlon et al., 2009). Many metrics, especially of the hill numbers, are contingent on sampling effort changes, while others (i.e., mass per individuals of functional guilds) are cumbersome to collect all the data necessary (e.g., species ID, individual masses, functional role, etc.). Consensus among studies is that using multiple, ideally disparate, metrics helps gain a better understanding of the changes that occurred to the system (Morris et al., 2014). Lyashevka and Farnsworth (2012) suggest using at least three metrics differentiated to cover taxonomic (or genetic), functional, and structural (abundance or biomass) aspects of the species assemblage, as Richness alone misses some $88.6 \%$ of information. In accordance with this, greater understanding of shifts in the fish assemblage of the CAWS can be gained by comparing across different indices.

\subsection{Index specificities}

Indices which account for species identity, such as the analysis of anomalies and their CUSUM, are thought to be more sensitive to assessing perturbation and regime shifts (Andersen et al., 2009; Magurran and Henderson, 2010; Nicholls, 2011). However, in this analysis, comparing breakpoints in the CUSUM metric to others suggests it focused heavily on changes to the Gizzard Shad population. For example, the CUSUM metric's breakpoints for 1987 and 2016 coincide with breakpoints for mass per individual of planktivores, abundance anomalies,, and changes in Gizzard Shad abundances (at least for 2016). As Gizzard Shad are both highly abundant and the primary planktivore, the CUSUM analysis appears highly sensitive to changes in this numerically dominant species. Conversely, several indices had breakpoints in the late 1990's, including multiple trophic guild's mass per individual data. Beginning in 1997, capture rates appear low across multiple species (Figs. 8 and 9). A streak of five years without White Suckers (Catostomus commersonii) began in 1997, which was also a year without Pumpkinseed (Lepomis gibbosus), Hybrid Lepomids, as well as low Bluegill captures (Figs. 8 and 9). Changes to how and where MWRD sampled fish 1997 through 2001 do not fully explain the differences noted in species catches and biomasses for these years, nor the assemblage level diversity metric trends. These noted species-level responses likely account for why the lowest Shannon's H, Evenness, and Gini-Simpson numbers all occurred in 1997. This consensus-type analysis yields a greater understanding of what changed and when within the fish assemblage of the CAWs than using a single metric to describe diversity alone.

Few studies have related taxonomic distinctness $\left(\Delta^{+}\right)$of freshwater fish assemblages to ecosystem degradations, but those that have suggest that it provides a reliable bioassessment metric (Bhat and Magurran, 2006; Jiang et al., 2020), but with low resolution (Piperac et al., 2016). Recent work with freshwater invertebrates suggests traditional diversity metrics (i.e., Shannon-Wiener H) may be more sensitive to known 


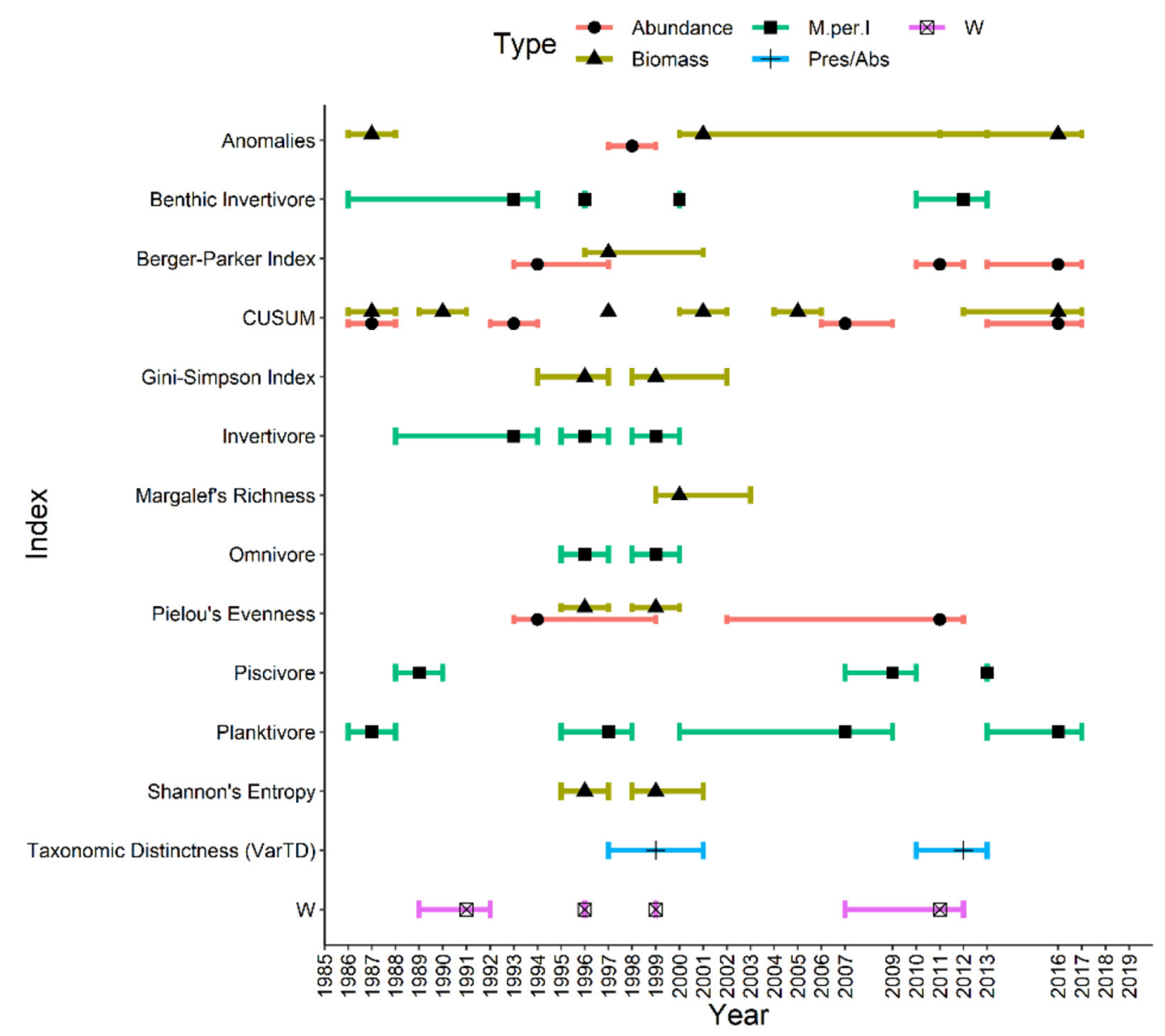

Fig. 7. Breakpoints, and $95 \%$ confidence intervals, in various metrics used to describe diversity of the Chicago Area Waterway System fish assemblage suggest significant changes to the assemblage in late 1990s. Symbols and colors used to denote what type of data was used to calculate the index on the $y$-axis as some metrics were calculated separately using abundance and biomass datasets.

environmental degradation than taxonomic distinctness $\left(\Delta^{+}\right)$ (Ji et al., 2020; Piperac et al., 2018). Linear increases were noted with taxonomic distinctness $\left(\Delta^{+}\right)$across the timeseries, in line with many of the more traditional diversity metrics suggesting increasing environmental quality from 1985 to 2019. Slow and continual species additions to the system are to be expected if dispersal into the CAWs is limited by both environmental quality (e.g., water and habitat degradation; (LimnoTech, 2010) as well as physical barriers (i.e., the lock and dam system). Being that many species in urbanized freshwater systems are from three orders, i.e., Cyprinformes, Perciformes, and Siluriformes, it is not all too surprising that taxonomic distinctness $\left(\Delta^{+}\right)$does not provide much insights into breakpoints in assemblage structure over time (e.g., replacement of one cyprinid with another). For a breakpoint to occur in taxonomic distinctness $\left(\Delta^{+}\right)$a rapid proliferation of species within a regionally present but locally absent order (Retzer, 2005; e.g., Acipenseriformes, Lepisosteiformes or Scorpaeniformes; Retzer and Batten, 2005) or the near elimination of a dominant order (i.e., Cypriniformes or Perciformes) would be required, yet are equally unlikely to occur. Perhaps policy and management changes focused on water quality issues, stemming from waste- and storm-water systems, have attained an associated maximum level of higherlevel taxonomic changes possible. Additions of more taxonomically distinct species may require enhancements to habitat variables and increased dispersal capacities (i.e., dam removals or fishways (Kanehl et al., 1997) combined with maintenance of improved water quality metrics.

The Abundance-Biomass Curves (aka. ABC method or Warwick's W Statistic) provides a measure of community level changes thought to be interpretable on a level from disturbed (negative $\mathrm{W}$ values; higher abundances than biomass) to undisturbed (positive $\mathrm{W}$ values; higher biomass than abundance) (Clarke and Warwick, 2001b; Warwick and Clarke, 1994). Although initially developed with macroinvertebrates, comparisons between the $\mathrm{W}$ statistic of freshwater fish assemblages and water quality metrics suggests it is correlated with indicators of poor water quality (i.e., phosphorous, nitrogenous compounds, low dissolved oxygen), as long as other habitat variables are accounted for (Coeck et al., 1993; Pinto et al., 2006; Piperac et al., 2015; Villanueva and Ibarra, 2016), but apparently not metal pollutants (i.e., cadmium and zinc, Bervoets et al., 2005). The majority of $\mathrm{W}$ values for the fish assemblage of the CAWS were only slightly positive values (generally $\leq 0.25$ ), suggesting a low level of 


\section{CPUE $(\ln (n+1)) \quad 123456$}

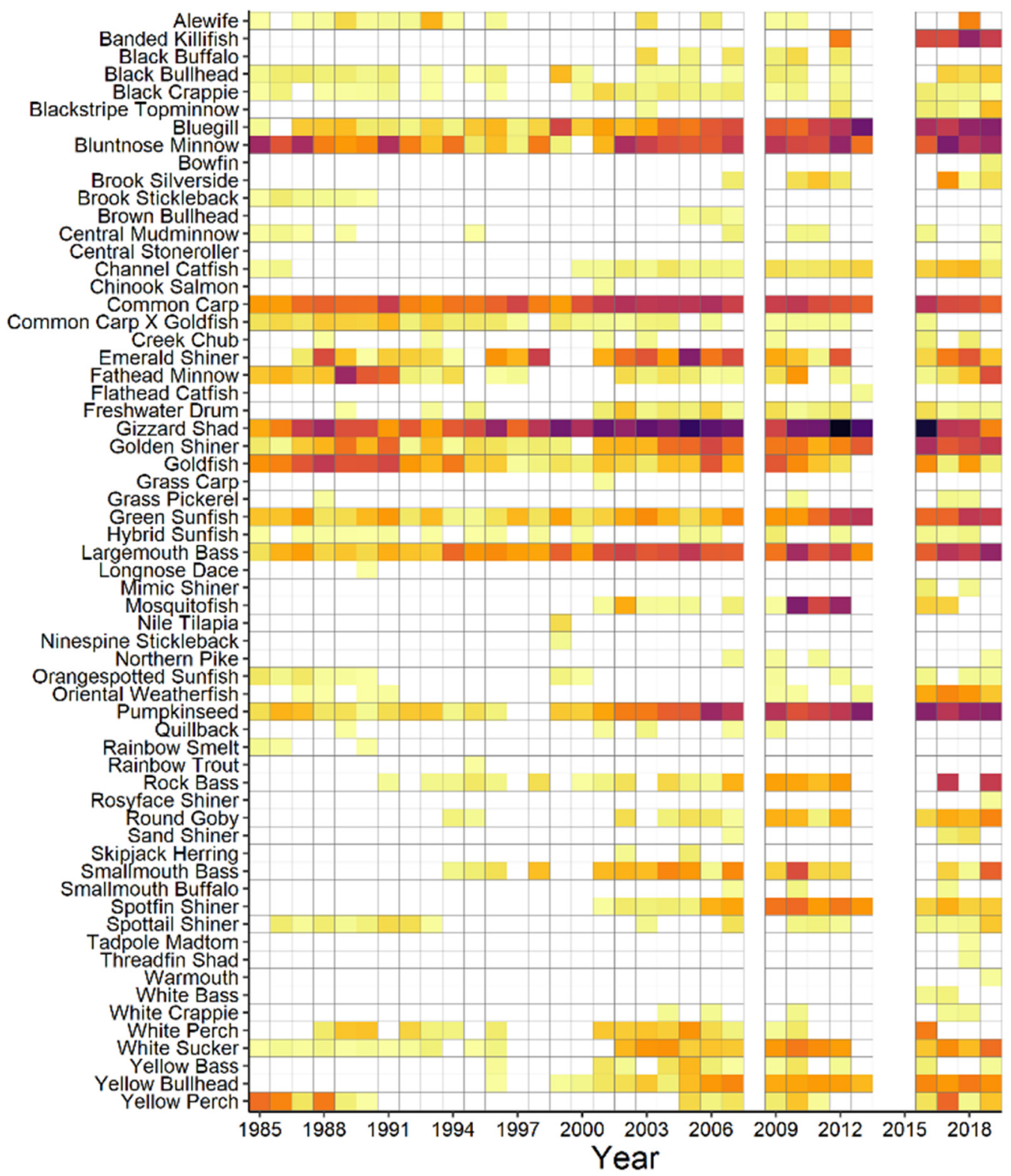

Fig. 8. Changes in mean $\log _{\mathrm{e}}$ transformed abundances (CPUEs) of 62 fish species caught in the Chicago Area Waterway System in $1985-2019$.

degradation but not necessarily strong indication of a system with many long-lived, large, individuals (i.e., an undegraded system). For context, a study comparing polluted $v$ s. reference freshwater sites found the reference site to have a W statistic of only $0.30 \mathrm{vs}$. -0.09 and -0.12 at polluted sites (Villanueva and Ibarra, 2016), and data in this study maintained a positive mean value (0.196) whilst varying in yearly trends. When only the largely habitat invariable Chicago Sanitary and Ship Canal and Lockport Lock and Dam areas were sampled, and large abundances of small Lepomis spp. were found, the lowest W statistic value was observed $(W=-0.04$; year $=2013)$. Similarly, low values in 1999 and 2012 appear to be related to large abundances of smaller Gizzard Shad, Lepomis spp., and in 2012
Banded Killifish (Fundulus diaphanus). As such, the W statistic may be sensitive to changes in recruitment, especially of numerically dominant species. Overall, the W statistic did not suggest a trend towards a non-degraded fish assemblage over the 35 year timeseries like other diversity metrics did, but instead indicates that small-sized individuals are equally, or more, prevalent compared to larger, older, individuals in the CAWs.

\subsection{Caveats and confounding factors}

An altered, and reduced sampling scheme in 1997-2000 years does not fully explain the breakpoints in biomasscalculated indices noted in the timeframe. Only $1 / 2$ of the 


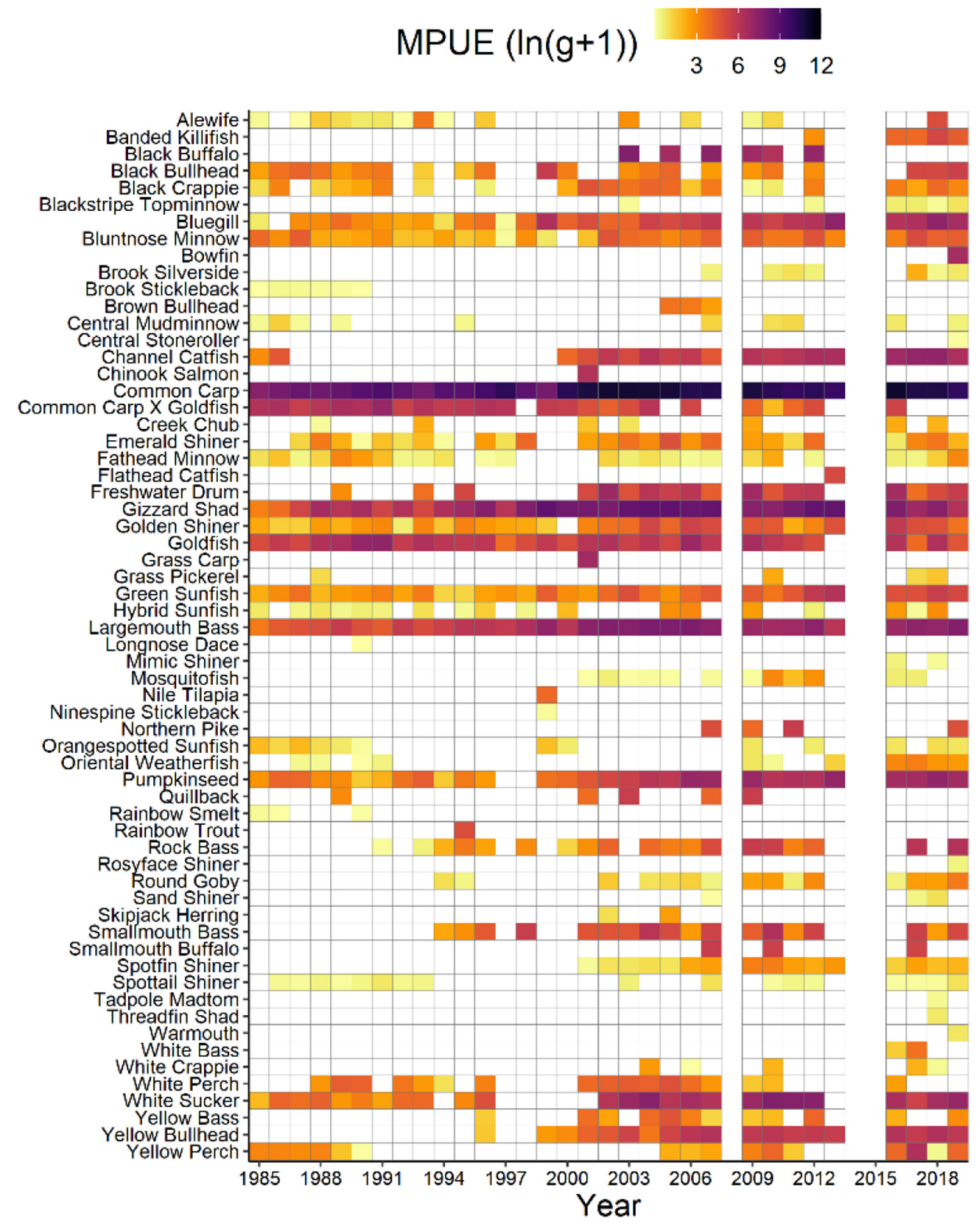

Fig. 9. Changes in mean $\log _{\mathrm{e}}$ transformed biomass (mass per unit effort, MPUE) of 62 fish species caught in the Chicago Area Waterway System in $1985-2019$.

waterways were sampled in 1997, 1998, 2000 and different waterway combinations in each of those years, with only the North Shore Channel being sampled in 1999 (Table S1.1 in Appendix S1). Interestingly, of these four years, 1999 had the highest values for many traditional diversity metrics (i.e., Shannon's Entropy, Pielou's Evenness, and Gini-Simpson Index) calculated on biomass despite representing a single waterway. Happel and Gallagher (2021) noted that fish CPUEs of each of the six waterways studied in the CAWS were different from each other, with the Calumet and Little Calumet Rivers having greater species Richness than other sites.
Neither the Calumet River nor Little Calumet River were sampled in 1997, 1999, or 2000, but with 1997 having the lowest and 1999 the highest diversity values the absence of these locations does not explain the differences in resultant biomass diversity. Instead, the Cal-Sag Channel, Chicago Sanitary and Ship Canal, and Lockport Lock and Dam locations were sampled in 1997, suggesting that these large, channelized areas are lacking diversity in energy transfers, i.e., biomass. In 2000, the Chicago Sanitary and Ship Canal, Lockport Lock and Dam, and North Shore Channel were all sampled, and these data were considered more reflective of 
several years following, where all waterways were sampled consistently. Between 2001 and the late 2010's traditional diversity metrics (i.e., Shannon's Entropy, Pielou's Evenness, and Gin-Simpson Index) calculated on biomass increased to match the 1999 value from the North Shore Channel. This could be interpreted as the biomass diversity of the large, channelized sections of the CAWS has increased over time to mirror or match other sections of the CAWS.

Beginning in 2001, pulsed-DC electrofishing was used to sample fish communities whereas previously AC electrofishing was used. Only Margalef's Richness on biomasses appears to have been rather sensitive to this methodology change. Without other indices identifying a breakpoint between 2000 and 2001, it is difficult to describe the effects this shift in sampling methodology had on the dataset. While it is thought that DC electrofishing may capture more benthic dwelling species (i.e., Catostomidae and Ictaluridae), both families were captured prior to 2001 in the CAWS. A direct comparison of AC and DC fishing methods conducted on the Illinois River indicated that CPUE and richness were higher with DC fishing (McClelland et al., 2013). McClelland et al. (2013) indicated that larger individuals of most species were captured with DC fishing and could explain why Margalef's Richness calculated with biomass was sensitive to the shift from AC to DC in 2000. Interestingly, traditional diversity metrics calculated on abundances and taxonomic distinction $\left(\Delta^{+}\right)$were robust to the methodology change. These results concur with other studies indicating that abundance and biomass datasets provide different views of assemblage structuring, and consideration should be given to what data is used in calculations (Connolly et al., 2005; Henderson and Magurran, 2010; Morlon et al., 2009).

Data pre-treatment and standardization can play a large role in how calculated indices compare two species communities. This is of particular concern for the calculation intensive anomalies and CUSUM analyses, both of which use Bray-Curtis similarities which are known to be sensitive to how data is treated (Legendre and Gallagher, 2001; Noy-Meir et al., 1975). Despite a strong transformation (log transformation) to reduce the influence of dominant species in Bray-Curties similarity calculations, Gizzard Shad were still overly influential in the behavior of both the anomalies and CUSUM indices. Data pre-treatment remains a topic of discussion when working with multivariate data (Clarke et al., 2014; Happel et al., 2017), likely because the level standardization and strength of transformation will depend on the researcher's interests. The CUSUM analysis itself is a transformation of the data (i.e., summation of residuals around the mean), and although it inflates the visibility of transitions in a timeseries (Adrian et al., 2006), it has also been shown to inflate correlations which are not supported by raw data (Cloern et al., 2012). As such, it is recommended that caution should be given when using CUSUM transformations, or anomalies analysis, to assess shifts in species assemblages.

\subsection{Recommendations and conclusions}

Strategies to diversify the piscivore guild, as well as increase the mass per individual, may be a useful management goal for the CAWS. Species of Amiiformes, Esociformes and Lepisosteiformes are regionally present but generally low in abundance or missing from the CAWS (Retzer, 2005; Slawski et al., 2008), and colonization would increase average taxonomic distinctness $\left(\Delta^{+}\right)$and decrease variation in taxonomic distinctness $\left(\Lambda^{+}\right)$, both trends indicative of less degradation (Clarke and Warwick, 1999, 2001b). Increasing biomass per individual piscivore would also increase the $\mathrm{W}$ statistic of system signaling less degradation (Warwick and Clarke, 1994). For example, the biomass of Largemouth Bass captured each year does not appear to have increased since circa 1997 despite increases in abundance (Figs. 6 and 7). The lack of biomass change combined with increases in abundance of Largemouth Bass contributes to the decreasing trend in mass per individual of the piscivore guild. Management strategies for such outcomes would likely need to focus on habitat-related initiatives as urban rivers such as the CAWS are relatively habitat invariable (Francis, 2009), and habitat has been suggested as a limiting factor for the CAWS in particular (LimnoTech, 2010).

Specific regimes, or specific mean species compositions held for several years, in the fish assemblage of the CAWS were not noted and perhaps are not to be expected. Step changes in means of an index has most commonly been used to assess regime shifts (Andersen et al., 2009), especially in climatology (Rodionov, 2004) and studies of the North Pacific (Overland et al., 2008). However, the underlying stressors of system must remain semiconstant for the establishment of a mean species composition, or regime. As measures, policies, and social norms around water quality of surface waters has changed semi continuously over the period of time of study, it seems unlikely for a specific regime to have time to establish in the fish assemblage of the CAWS. Instead, it is noted that new populations appear and grow throughout the timeseries, similar to that noted over the $\sim 60$-year timeseries from the Illinois River system downstream of the CAWS by (DeBoer et al., 2019). Together, these reports suggest that fish assemblages of highly modified rivers (i.e., the CAWS and Illinois River) exhibit complex non-linear responses to multiple stressors as well as their amelioration. Continued work to recognize trends and lags in species response as well as incorporating them in modelling efforts may increase abilities to predict responses to restoration efforts (Bernhardt and Palmer, 2011; Clements et al., 2010; Poole et al., 2004).

I provide evidence for continual increases in diversity (i.e., non-steady state regimes) across 35 years, as well as piecewise trends in an urban freshwater system's fish assemblage. Taken together these results can be interpreted as indicative of an ecosystem of increasing quality without periods of steady-state regime structuring. Time was used as the dependent variable, and others have shown time to adequately act as a proxy for water quality downstream on the Illinois River (DeBoer et al., 2019; Parker et al., 2018). It is important to emphasize that time itself is not a driver of assemblage re-structuring in an environment. A complex combination of environmental variables, moderated by social norms, policies and contracts, acts the driver of species responses (Mac Nally et al., 2014; Ormerod et al., 2010). Monitoring and assessing ecosystem responses to such complex combinations of stressors/pressures through long-term monitoring projects is a primary step in identifying thresholds of regime shifts and will help manage and enhance such urbanized systems in the global future (Andersen et al., 2009). Further analyses of long-term trends in water chemistry, habitat quality, social norms, as well as policy-level changes may illuminate the dominant drivers of the identified shifts. 


\section{Data accessibility statement}

All data included in this study are publicly available from the Metropolitan Water Reclamation District of Greater Chicago upon request and without restrictions.

\section{Supplementary Material}

\section{Appendix S1}

Table S1.1 The number of unique samples, 400ft samples, taken each year from each waterway.

Figure S1.1 Increases in storage capacity of Mainstem and Calumet sections of Chicago's Tunnel and Reservoir Plan as well as actions taken to improve water quality in those sections of the Chicago Area Waterway System.

\section{Appendix S2}

Table S2.1 List of species found within the Chicago Area Waterway System between 1985-2019 in July - September at nine locations representing six waterways.

The Supplementary Material is available at https://www.kmae. org/10.1051/kmae/2021038/olm.

Acknowledgements. This work would not have been possible without the Metropolitan Water Reclamation District of Greater Chicago whom conducted the field work and graciously shared their data and thoughts on the research. I extent special thank you' $s$ to Dustin Gallagher, Thomas Minarik, Jessica Wasik, and Justin Vick with whom provided data, comments, suggestions, and feed back on several aspects of the work. Andy Kough, Melissa Youngquist, and Lynn Waterhouse provided feedback on earlier versions of the manuscript. Two anonymous reviewers helped increase structure and readability of the manuscript.

\section{References}

Adrian R, Wilhelm S, Gerten D. 2006. Life-history traits of lake plankton species may govern their phenological response to climate warming. Global Change Biol 12: 652-661.

Albert JS, Destouni G, Duke-Sylvester SM, et al. 2020. Scientists' warning to humanity on the freshwater biodiversity crisis. Ambio. https://doi.org/10.1007/s13280-020-01318-8

Andersen T, Carstensen J, Hernández-García E, Duarte CM. 2009. Ecological thresholds and regime shifts: approaches to identification. Trends Ecol Evol 24: 49-57

Barbour MT. 1999. Rapid bioassessment protocols for use in wadeable streams and rivers: periphyton, benthic macroinvertebrates and fish. US Environmental Protection Agency, Office of Water.

Bernhardt ES, Palmer MA. 2011. River restoration: the fuzzy logic of repairing reaches to reverse catchment scale degradation. Ecol Appl 21: 1926-1931.

Bervoets L, Knaepkens G, Eens M, Blust R. 2005. Fish community responses to metal pollution. Environ Pollut 138: 338-349.

Bestelmeyer BT, Ellison AM, Fraser WR, et al. 2011. Analysis of abrupt transitions in ecological systems. Ecosphere 2: art129.
Bhat A, Magurran AE. 2006. Taxonomic distinctness in a linear system: a test using a tropical freshwater fish assemblage. Ecography 29: 104-110.

Booth DB, Roy AH, Smith B, Capps KA. 2016. Global perspectives on the urban stream syndrome. Freshw Sci 35: 412-420.

Bouska KL, Houser JN, De Jager NR, et al. 2020. Conceptualizing alternate regimes in a large floodplain-river ecosystem: water clarity, invasive fish, and floodplain vegetation. JEnviron Manag 264: 110516.

Burdis RM, DeLain SA, Lund EM, Moore MJC, Popp WA. 2020. Decadal trends and ecological shifts in backwater lakes of a large floodplain river: Upper Mississippi River. Aquatic Sci 82. https:// doi.org/10.1007/s00027-020-0703-7

Butts TA, Shackleford DB, Bergerhouse TR. 1999. Evaluation of reaeration efficiencies of sidestream elevated pool aeration (SEPA) stations. ISWS Contract Report CR-653.

Capon SJ, Chambers LE, Mac Nally R, et al. 2013. Riparian ecosystems in the 21st century: hotspots for climate change adaptation? Ecosystems 16: 359-381.

Capon SJ, Lynch AJJ, Bond N, et al. 2015. Regime shifts, thresholds and multiple stable states in freshwater ecosystems; a critical appraisal of the evidence. Sci Total Environ 534: 122-130.

Clarke KR, Gorley RN. 2015. Primer, V7. In User Manual/Tutorial (7.0).

Clarke KR, Tweedley JR, Valesini FJ. 2014. Simple shade plots aid better long-term choices of data pre-treatment in multivariate assemblage studies. J Mar Biol Assoc UK 94: 1-16.

Clarke KR, Warwick RM. 1999. The taxonomic distinctness measure of biodiversity: weighting of step lengths between hierarchical levels. Mar Ecol Progr Ser 184: 21-29.

Clarke KR, Warwick RM. 2001a. A further biodiversity index applicable to species lists: variation in taxonomic distinctness. Mar Ecol Progr Ser 216: 265-278.

Clarke KR, Warwick RM. 2001b. Changes in marine communities: an approach to statistical analysis and interpretation. Plymouth: Plymouth Marine Laboratory.

Clements WH, Vieira NKM, Sonderegger DL. 2010. Use of ecological thresholds to assess recovery in lotic ecosystems. J North Am Bentholog Soc 29: 1017-1023.

Cloern JE, Jassby AD, Carstensen J, et al. 2012. Perils of correlating CUSUM-transformed variables to infer ecological relationships (Breton et al. 2006; Glibert 2010). Limnol Oceanogr 57: 665-668.

Coeck J, Vandelannoote A, Yseboodt R, Verheyen RF. 1993. Use of the abundance/biomass method for comparison of fish communities in regulated and unregulated lowland rivers in Belgium. Regul Rivers: Res Manag 8: 73-82.

Connell JH, Sousa WP. 1983. On the evidence needed to judge ecological stability or persistence. Am Natural 121: 789-824.

Connolly SR, Hughes TP, Belwood DR, Karlson RH. 2005. Ecology: Community structure of corals and reef fishes at multiple scales. Science 309: 1363-1365.

DeBoer JA, Thoms MC, Casper AF, Delong MD. 2019. The response of fish diversity in a highly modified large Rriver system to multiple anthropogenic stressors. J Geophys Res Biogeosci 124: 384-404.

deYoung B, Barange M, Beaugrand G, et al. 2008. Regime shifts in marine ecosystems: detection, prediction and management. Trends Ecol Evolut 23: 402-409.

Dodds WK, Robinson CT, Gaiser EE, et al. 2012. Surprises and insights from long-term aquatic data sets and experiments. BioScience 62: 709-721.

Everard M, Moggridge HL. 2012. Rediscovering the value of urban rivers. Urban Ecosyst 15: 293-314. 
Fausch KD, Lyons J, Karr JR, Angermeier PL. 1990. Fish communities as indicators of environmental degradation. Am Fish Soc Symp 8: 123-144.

Folke C, Carpenter S, Walker B, et al. 2004. Regime shifts, resilience, and biodiversity in ecosystem management. Annu Rev Ecol Evol Syst 35 .

Fore A. 2015a. Greater Chicago Historic Infrastructure Projects Enhance Windy City Water Quality. Wateronline.Com. https:// www.wateronline.com/doc/greater-chicago-historic-infrastruc ture-projects-enhance-windy-city-water-quality-0001

Fore A. 2015b. Press Release Disinfected Water Begins Flowing to Chicago River System from MWRD's Calumet Plant.

Francis RA. 2009. Perspectives on the potential for reconciliation ecology in urban riverscapes. CAB Reviews: Perspectives in Agriculture, Veterinary Science, Nutrition and Natural Resources 4: 1-20.

Gallardo B, Gascón S, Quintana X, Comín FA. 2011. How to choose a biodiversity indicator-redundancy and complementarity of biodiversity metrics in a freshwater ecosystem. Ecol Indic 11: 11771184.

Giblin SM. 2017. Identifying and quantifying environmental thresholds for ecological shifts in a large semi-regulated river. J Freshw Ecol 32: 433-453.

Gibson-Reinemer DK, Sparks RE, Parker JL, et al. 2017. Ecological recovery of a river fish assemblage following the implementation of the Clean Water Act. BioScience 67: 957-970.

Gordon LJ, Peterson GD, Bennett EM. 2008. Agricultural modifications of hydrological flows create ecological surprises. Trends Ecol Evol 23: 211-219

Greenberg J. 2004. A natural history of the Chicago region. University of Chicago Press.

Happel A, Czesny S, Rinchard J, Hanson SD. 2017. Data pretreatment and choice of resemblance metric affect how fatty acid profiles depict known dietary origins. Ecol Res 32: 757-767.

Happel A, Gallagher D. 2021. Chicago's fish assemblage over 30 years - more fish and more native species. Urban Ecosyst 24: $311-$ 325 .

Henderson PA, Magurran AE. 2010. Linking species abundance distributions in numerical abundance and biomass through simple assumptions about community structure. Proc R Soc B 277: 15611570 .

Hill L. 2019. The Chicago River: a natural and unnatural history. Southern Illinois University Press.

Holling CS. 1973. Resilience and stability of ecological systems. Annu Rev Ecol Syst 4: 1-23.

Illinois Coastal Management Program. 2011. Illinois Coastal Management Program Issue Paper: Chicago River and North Shore Channel Corridors. http://www.chicagoareawaterways.org/ documents/CAWS-UAA-DRAFT-REPORT.pdf

Ji L, Jiang X, Liu C, et al. 2020. Response of traditional and taxonomic distinctness diversity indices of benthic macroinvertebrates to environmental degradation gradient in a large Chinese shallow lake. Environ Sci Pollut Res 27: 21804-21815

Jiang X, Pan B, Sun Z, Cao L, Lu Y. 2020. Application of taxonomic distinctness indices of fish assemblages for assessing effects of river-lake disconnection and eutrophication in floodplain lakes. Ecol Indic 110: 105955.

Kanehl PD, Lyons J, Nelson JE. 1997. Changes in the habitat and fish community of the Milwaukee River, Wisconsin, following removal of the Woolen Mills Dam. North American J Fish Manag 17: $387-400$.

Karr JR, Dudley DR. 1981. Ecological perspective on water quality goals. Environ Manag 5: 55-68.
Legendre P, Gallagher ED. 2001. Ecologically meaningful transformations for ordination of species data. Oecologia 129: 271-280.

Lenth R, Singmann H, Love J. 2018. Emmeans: Estimated marginal means, aka least-squares means. $R$ package "emmeans" version 1.4.5.

LimnoTech. 2010. Chicago Area Waterway System Habitat Evaluation and Improvement Study: Habitat Evaluation Report.

Lyashevska O, Farnsworth KD. 2012. How many dimensions of biodiversity do we need? Ecol Indic 18: 485-492.

Mac Nally R, Albano C, Fleishman E. 2014. A scrutiny of the evidence for pressure-induced state shifts in estuarine and nearshore ecosystems. Aust Ecol 39: 898-906.

Magurran AE, Baillie SR, Buckland ST, et al. 2010. Long-term datasets in biodiversity research and monitoring: Assessing change in ecological communities through time. Trends Ecol Evol 25: $574-582$

Magurran AE, Henderson PA. 2010. Temporal turnover and the maintenance of diversity in ecological assemblages. Philos Trans Royal Soc B 365: 3611-3620.

McClelland MA, Irons KS, Sass GG, et al. 2013. A comparison of two electrofishing programmes used to monitor fish on the Illinois River, Illinois, USA. River Res Appl 29: 125-133.

Melching CS. 2018. Application of a water quality model for determining instream aeration station location and operational rules: a case study. Water Sci Eng 11: 8-16.

Morlon H, White EP, Etienne RS, et al. 2009. Taking species abundance distributions beyond individuals. Ecol Lett 12: 488-501.

Morris EK, Caruso T, Buscot F, et al. 2014. Choosing and using diversity indices: insights for ecological applications from the German Biodiversity Exploratories. Ecol Evol 4: 3514-3524.

MWRD. 2019. Stickney Water Reclamation Plant, Metropolitan Water Reclamation District of Greater Chicago Fact Sheet.

Nicholls KH. 2011. Detection of regime shifts in multi-species communities: The Bay of Quinte phytoplankton example. Methods Ecol Evol 2: 416-426.

Nicholls KH, Hoyle JA, Johannsson OE, Dermott R. 2011. A biological regime shift in the Bay of Quinte ecosystem (Lake Ontario) associated with the establishment of invasive dreissenid mussels. J Great Lakes Res 37: 310-317.

Noy-Meir I, Walker D, Williams WT. 1975. Data transformations in ecological ordination: II. On the meaning of data standardization. $J$ Ecol 779-800.

O'Hara M, Ickes BS, Gittinger EJ, Delain SA, Dukerschein T. 2007. Development of a life history database for Upper Mississippi River fishes. US Geological Survey.

Oksanen J, Blanchet FG, Friendly M, et al. 2019. "The vegan package". Community ecology package. R Package Version 2. 5-6. https://CRAN.R-project.org/package=vegan.

Olson KR, Morton LW. 2017. Chicago's 132-year effort to provide safe drinking water. $J$ Soil Water Conserv 72: 19A-25A.

Ormerod SJ, Dobson M, Hildrew AG, Townsend C. 2010. Multiple stressors in freshwater ecosystems. Freshw Biol 55, 1-4.

Overland J, Rodionov S, Minobe S, Bond N. 2008. North Pacific regime shifts: Definitions, issues and recent transitions. https://doi. org/10.1016/j.pocean.2008.03.016

Parker J, Cao Y, Sass GG, Epifanio J. 2018. Large river fish functional diversity responses to improved water quality over a 28 year period. Ecol Indic 88, 322-331.

Penczak T, Kruk A. 1999. Applicability of the abundance/biomass comparison method for detecting human impacts on fish populations in the Pilica River, Poland. Fish Res 39: 229-240. 
Pinto BCT, Peixoto MG, Araújo FG. 2006. Effects of the proximity from an industrial plant on fish assemblages in the rio Paraíba do Sul, southeastern Brazil. Neotrop Ichthyol 4: 269-278.

Piperac MS, Milošević D, Petrović A, Simić V. 2018. The best data design for applying the taxonomic distinctness index in lotic systems: a case study of the Southern Morava River basin. Sci Total Environ 610: 1281-1287.

Piperac MS, Milošević D, Simić S, Simić V. 2016. The utility of two marine community indices to assess the environmental degradation of lotic systems using fish communities. Sci Total Environ 551: 1-8.

Piperac MS, Milošević D, Simić V. 2015. The application of the abundance/biomass comparison method on riverine fish assemblages: limits of use in lotic systems. Biol Nyssana 6: 25-32.

Pluth TB, Brose DA, Gallagher DW, Wasik J. 2021. Long-term trends show improvements in water quality in the Chicago metropolitan region with investment in wastewater infrastructure, deep tunnels, and reservoirs. Water Resour Res 57: e2020WR028422.

Poff NL, Allan JD. 1995. Functional organization of stream fish assemblages in relation to hydrological variability. Ecology 76: $606-627$

Poole GC, Dunham JB, Keenan DM, et al. 2004. The case for regime-based water quality standards. BioScience 54: 155-161.

$\mathrm{R}$ Development Core Team. 2020. R: A language and environment for statistical computing. Version 3.6.3. R Foundation for Statistical Computing, Vienna, Austria. https://www.R-project.org/

Retzer ME. 2005. Changes in the diversity of native fishes in seven basins in Illinois, USA. Am Midland Natural 153: 121-134.

Retzer ME, Batten B. 2005. Fishes of the Chicago region: a review of the Dennison and Illinois Natural History Survey collections. Trans Illinois State Acad Sci 98: 63-73.

Richardson DM, Whittaker RJ. 2010. Conservation biogeography foundations, concepts and challenges. Divers Distrib 16: 313-320.

Roberts LR, Bishop IJ, Adams JK. 2020. Anthropogenically forced change in aquatic ecosystems: reflections on the use of monitoring, archival and palaeolimnological data to inform conservation. Geo: Geography and Environment 7: e00089.

Rodionov SN. 2004. A sequential algorithm for testing climate regime shifts. Geophys Res Lett 31.
Scheffer M, Carpenter SR. 2003. Catastrophic regime shifts in ecosystems: linking theory to observation. Trends Ecol Evol 18: 648-656.

Sheet MF. (n.d.). Tunnel and Reservoir Plan (TARP), Metropolitan Water Reclaimation District of Greater Chicago Fact Sheet.

Slawski TM, Veraldi FM, Pescitelli SM, Pauers MJ. 2008. Effects of tributary spatial position, urbanization, and multiple low-head dams on warmwater fish community structure in a midwestern stream. North Am J Fish Manag 28: 1020-1035

Solzman DM. 2006. The Chicago River: An illustrated history and guide to the river and its waterways. University of Chicago.

Villanueva MC, Ibarra AA. 2016. Assessing the ecological stress in a Garonne River stretch, southwest France. Ecol Indic 67: 466-473.

Vörösmarty CJ, McIntyre PB, Gessner MO, et al. 2010. Global threats to human water security and river biodiversity. Nature 467 : 555-561.

Walsh CJ, Roy AH, Feminella JW, et al. 2005. The urban stream syndrome: current knowledge and the search for a cure. J North Am Bentholog Soc 24: 706-723.

Warwick RM, Clarke KR. 1994. Relearning the ABC: taxonomic changes and abundance/biomass relationships in disturbed benthic communities. Mar Biol 118: 739-744.

Washington HG. 1984. Diversity, biotic and similarity indices: a review with special relevance to aquatic ecosystems. Water Res 18: 653-694.

Zeileis A, Kleiber C, Krämer W, Hornik K. 2003. Testing and dating of structural changes in practice. Comput Stat Data Anal 44: 109-123.

Zeileis A, Leisch F, Hornik K, Kleiber C. 2002. Strucchange: An R package for testing for structural change in linear regression models. J Stat Softw 7: 1-38

Zeileis A, Shah A, Patnaik I. 2010. Testing, monitoring, and dating structural changes in exchange rate regimes. Comput Stat Data Anal 54: 1696-1706.

Znachor P, Nedoma J, Hejzlar J, et al. 2018. Multiple long-term trends and trend reversals dominate environmental conditions in a manmade freshwater reservoir. Sci Total Environ 624: 24-33.

Cite this article as: Happel A. 2022. Increasing fish diversity of Chicago's waterways. Knowl. Manag. Aquat. Ecosyst., $423,6$. 